\title{
O jogo no ensino de Matemática: uma experiência com a revisão de conteúdos de trigonometria
}

\author{
Lucia Helena Costa Braz \\ Brenda Cristina Almeida \\ Leonardo Tavares Campos \\ Vinícius Silveira Ibrahim
}

\section{Resumo}

O presente trabalho intenciona apresentar resultados e reflexões acerca de uma experiência envolvendo o jogo como recurso didático no ensino de Matemática, realizada na Educação Básica. A partir da literatura estudada, acredita-se que o jogo é um instrumento que proporciona, ao aluno, trabalhar em grupo, comunicar com os colegas, compartilhar estratégias, aprender a obedecer a regras, o que faz com que o próprio aluno seja ativo em sua aprendizagem. A fim de exemplificar sua abordagem em sala de aula e criar um momento de estudo para o Exame Nacional do Ensino Médio (ENEM), foi aplicado o jogo Trigonometria para o ENEM, tendo como público alvo os alunos dos $4^{\circ}$ anos do Ensino Médio Integrado de uma escola pública da cidade de Formiga/MG. O jogo tem por finalidade trabalhar conteúdos de trigonometria, em especial as razões trigonométricas e semelhança de triângulos, com questões de vestibulares e do ENEM e, assim, fixar estes conteúdos através de um jogo, além de promover a socialização, interação entre os alunos e o raciocínio lógico-argumentativo, dedutivo e reflexivo. Os resultados mostraram que o jogo contribuiu para a fixação de alguns conceitos relacionados à trigonometria, pois a maioria dos alunos acertaram as questões propostas e demonstraram certo avanço nos mapas conceituais elaborados após a aplicação do jogo.

Palavras-chave: ensino de matemática; jogos; trigonometria; ENEM. 


\title{
The game in mathematics teaching: an experience with trigonometry content revision
}

\author{
Lucia Helena Costa Braz \\ Brenda Cristina Almeida \\ Leonardo Tavares Campos \\ Vinícius Silveira Ibrahim
}

\section{Abstract}

The present work intends to present results and reflections about an experience involving the game as a didactic resource in the teaching of Mathematics, carried out in Basic Education. From the literature studied, it is believed that the game is an instrument that allows the student to work in groups, communicate with colleagues, share strategies, learn to obey rules, which makes the student himself active in his learning. In order to exemplify its classroom approach and create a study moment for the National High School Exam (ENEM), the game Trigonometry for ENEM was applied, targeting students in the 4th grade of a public school in Formiga/MG. The game aims to work on trigonometry contents, especially the trigonometric reasons and similarity of triangles, with issues of vestibular and ENEM and thus fix these contents through a game, in addition to promoting socialization, interaction between students and the logical-argumentative, deductive and reflective reasoning. The results showed that the game contributed to the fixation of some concepts related to trigonometry, because most of the students got the proposed questions right and showed some progress in the conceptual maps prepared after the application of the game.

Keywords: math teaching; games; trigonometry; ENEM. 


\section{Introdução}

Embora a matemática seja um dos conhecimentos mais valorizados na sociedade moderna, ela também é, no geral, uma das disciplinas mais inacessíveis e produtora de fracassos, devido às dificuldades que os alunos apresentam no seu processo de aprendizagem (TEIXEIRA, 2004). Em especial, muitos alunos possuem dificuldades nos conteúdos de trigonometria, esta que é uma parte da Matemática com diversas aplicações científicas e tecnológicas (PEREIRA; GUERRA, 2016; DIONÍZIO; BRANDT, 2006).

Diante dessas dificuldades, muitas metodologias e recursos didáticos estão ganhando espaço no Projeto Pedagógico das escolas. E acreditamos que um dos recursos que pode auxiliar no processo de ensino e aprendizagem nas aulas de Matemática são os jogos. Grando (2000, p. 26) afirma que:

Ao analisarmos os atributos e/ou características do jogo que pudessem justificar sua inserção em situações de ensino, evidencia-se que este representa uma atividade lúdica, que envolve o desejo e o interesse do jogador pela própria ação do jogo, e mais, envolve a competição e o desafio que motivam o jogador a conhecer seus limites e suas possibilidades de superação de tais limites, na busca da vitória, adquirindo confiança e coragem para se arriscar.

No entanto, muitos professores não utilizam desse recurso, uma vez que a maioria das aulas são expositivas, como destaca D’Ambrósio (1989, p.15): "sabe-se que a típica aula de matemática a nível de primeiro, segundo e terceiro graus ainda é uma aula expositiva, em que o professor passa para o quadro negro aquilo que ele julga importante".

Sendo assim, como futuros docentes, buscamos, nas oportunidades de regência que temos, estágio, em atividades do Programa Institucional de Bolsas de Iniciação à Docência (PIBID), entre outras - por diferentes recursos e metodologias, a fim de vivenciarmos e refletirmos acerca desta experiência enquanto ainda nos encontramos no processo de formação. Nesse sentido, sabendo da importância da trigonometria e a fim de auxiliar os alunos nos estudos para o Exame Nacional do Ensino Médio (ENEM), adaptamos um jogo para trabalharmos alguns conteúdos de trigonometria.

O objetivo deste artigo é, a partir da literatura sobre o uso de jogos no ensino de Matemática, relatar e refletir acerca de uma experiência com o uso de jogo ao utilizá-lo em uma atividade ofertada para os alunos dos $4^{\circ}$ anos do Ensino Médio Integrado aos Cursos Técnicos em Administração, Eletrotécnica e Informática, em uma instituição pública da cidade de Formiga/MG. O objetivo da atividade era trabalhar conteúdos de trigonometria, em especial as razões trigonométricas e semelhança de triângulos, com questões de vestibulares e do ENEM e, assim, fixar estes conteúdos através de um jogo, além de promover a socialização, interação entre os alunos e o raciocínio lógico-argumentativo, dedutivo e reflexivo. 


\section{O uso de jogos na sala de aula}

O uso de jogos no ensino da matemática tem sido uma possibilidade estudada por diversos autores (GRANDO, 2000; JELINEK,2005; ALVES, 2007; BORIN, 2007). Além de propiciar o "aprender brincando", destacado por Grando (2000), "Os jogos são exemplos de atividades que envolvem várias habilidades matemáticas, como a lógica, a memória, a percepção visual, além do que, conteúdos matemáticos específicos podem ser trabalhados” (BARBOSA et al, 2015, p. 72).

Os jogos também podem possibilitar uma mudança no processo de ensino pois, enquanto, para o professor, em aulas tradicionais, ele apenas transmite o conhecimento de forma concreta, com o uso de jogos, ele pode passar a estimular o aluno a construir seu próprio conhecimento. Já o aluno, que antes só recebia as informações, pode se tornar agente principal de seu conhecimento. Segundo Jelinek (2005, p. 23), "essa educação, consequentemente, se tornará mais interessante e prazerosa para o aluno, e eficiente para o professor”.

A autora chama atenção para o fato de que é notório que os jogos evidenciam o caráter lúdico, mas destaca que é necessária clareza com relação ao seu objetivo para que, no momento de selecioná-lo ou construí-lo, este seja o mais adequado para os alunos e para que os mesmos percebam o conteúdo trabalhado e desconstrua o pensamento de que o jogo é apenas para diversão.

E ainda, para que os objetivos de uma atividade com jogos sejam alcançados, cabe ao professor assumir o papel intermediário durante a aplicação de um jogo. Nesse sentido, Grando (1995, p. 97) sugere “[...] que o professor não se isole do processo, mas que seja elemento integrante, ora como observador, juiz e organizador, ora como questionador, enriquecendo o jogo, mas evitando interferir no seu desenrolar. Portanto, como um elemento mediador entre os alunos e o conhecimento [...]”.

Dos efeitos que o jogo pode gerar para o ensino e aprendizagem na sala de aula, Alves (2007) pontua que "a educação por meio de atividades lúdicas vem estimulando as relações cognitivas, afetivas, sociais, além de propiciar também atitudes de crítica e criação nos alunos que se envolvem nesse processo" (ALVES, 2007, p. 22).

O jogo também proporciona ao aluno trabalhar em grupo, comunicar com os colegas, compartilhar estratégias, aprender a obedecer a regras, o que faz com o aluno seja ativo em sua aprendizagem. Segundo Selva e Camargo (2009, p. 4), “o jogo é um processo, no qual o aluno necessita de conhecimentos prévios, interpretação de regras e raciocínio, o que representa constantes desafios".

No decorrer de um jogo, segundo Borin (2007), os alunos fazem suas jogadas e, consequentemente, frente à um resultado correto ou não, assim é possível descobrir uma estratégia com base nas conclusões de jogadas anteriores e novas hipóteses. Segundo a autora, os erros também são favoráveis no decorrer de um jogo, pois diante deles o aluno precisa 
encontrar uma nova maneira de resolver o problema proposto e, assim, terá de utilizar outro raciocínio com base em seus conhecimentos prévios.

Essas características que a utilização de jogos possui favorecem o desenvolvimento do raciocínio lógico e pensamento crítico-científico, questão que favorece consideravelmente na hora de colocar em prática a resolução de problemas, por exemplo. Jelinek (2005, p.142) afirma que "durante o jogo o educando desenvolve-se cognitivamente, pois é obrigado a pensar e a estabelecer estratégias, desenvolvendo assim, o pensamento lógico e a autonomia”.

Quando se fala em jogos no ensino, é importante destacar que, num primeiro momento, estes se tornam um atrativo para os alunos e isso acaba gerando certa desorganização na sala de aula, pois a competitividade acaba sendo um estímulo e um incentivo para o jogo. No entanto, Borin (2007) aponta que o barulho é algo que faz parte do processo de aplicação de um jogo, afinal, a socialização e a interação são, também, objetivos.

Alves (2007, p.58) destaca que é importante que os objetivos estejam bem definidos, a proposta clara e bem organizada para que os alunos não a tratem como uma simples brincadeira e, então, possam se preocupar em aprender o conteúdo trabalhado, além de não se correr o risco de a atividade ser transformada "em apenas um instrumento de valorização do pensamento mecânico e algorítmico" (ALVES, 2007, p.58).

Portanto, acredita-se que os jogos auxiliam na construção do conhecimento do aluno, pois além de desenvolver habilidades, como o raciocínio lógico, ele também poderá estar fixando ou até mesmo aprendendo novos conteúdos.

\section{Descrição do caso}

A atividade foi desenvolvida no dia 23 de fevereiro de 2018 no Instituto Federal de Educação, Ciência e Tecnologia de Minas Gerais (IFMG) - campus Formiga durante os Cursos de Verão ofertados pela instituição, e contou com uma carga horária de 3 horas.

A atividade teve como público alvo os alunos dos $4^{\circ}$ anos do Ensino Médio Integrado do campus, e contou com a participação de seis ${ }^{3}$ alunas, sendo três do Curso Técnico em Administração e três do Curso de Técnico em Eletrotécnica. Das 6 alunas, uma era do $2^{\circ}$ ano ${ }^{4}$, duas eram do $3^{\circ}$ ano, e as três restantes eram do $4^{\circ}$ ano. As alunas tinham entre 16 a 18 anos, e apenas uma não havia participado de aula com jogos. O objetivo da atividade era trabalhar conteúdos de trigonometria, em especial as razões trigonométricas e semelhança de triângulos, com questões de vestibulares e do ENEM e, assim, fixar estes conteúdos através de um jogo,

3 Para preservar a identidade dos alunos, a referência aos mesmos, no texto, se dará por aluno 1, aluno $2, \ldots$, aluno 6.

${ }^{4} \mathrm{~A}$ atividade tinha como público alvo os alunos dos $4^{\circ}$ anos, mas os alunos das outras turmas também podiam participar. 
além de promover a socialização, interação entre os alunos e o raciocínio lógico-argumentativo, dedutivo e reflexivo.

\section{O jogo trigonometria para o ENEM}

O jogo Trigonometria para o ENEM é uma adaptação do jogo Fórmula Mundy (SILVA, 2013) e tende a promover o desenvolvimento do raciocínio lógico-argumentativo, dedutivo e reflexivo através da resolução de exercícios que envolvem questões de trigonometria de níveis básico, intermediário e avançado, sendo que as questões do nível básico eram do Ensino Fundamental, as questões do nível intermediário eram baseadas no conteúdo do Ensino Médio e as do último nível, avançado, eram questões de provas do ENEM.

É um jogo sugerido para que professores trabalhem com alunos que estão se preparando para vestibulares e, principalmente, para o ENEM, ou seja, recomendado para alunos do Ensino Médio.

O jogo é composto por: um tabuleiro redondo, dois carrinhos, as cartas dos diferentes níveis, as cartas SORTE e dois cadernos de questões iguais, um para cada aluno.

Figura 1. Tabuleiro do Jogo Trigonometria para o ENEM e Materiais do jogo sobre a mesa.
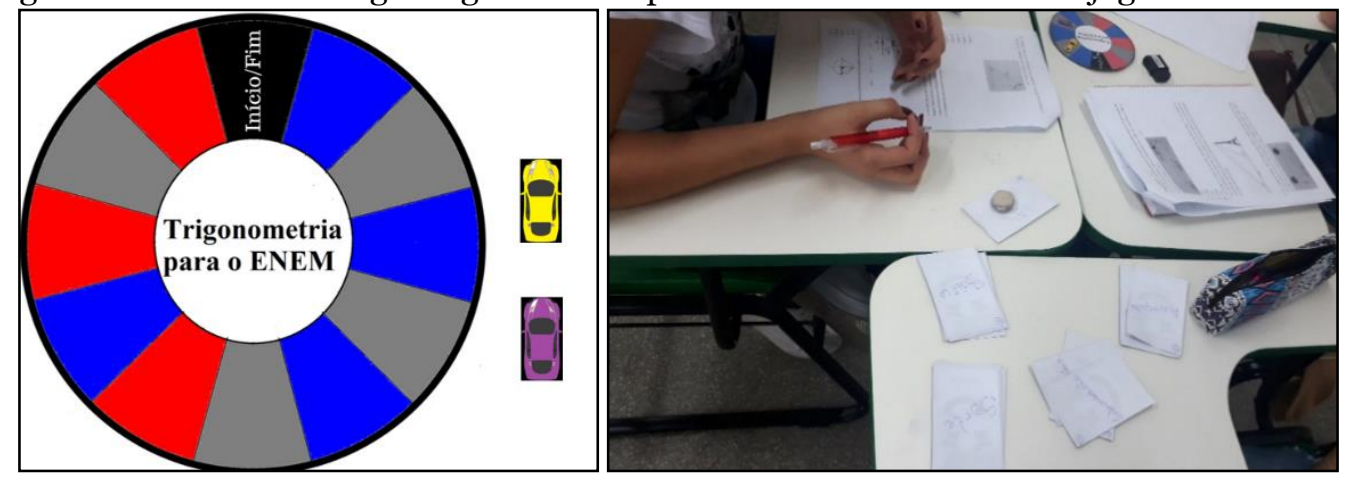

Fonte: Próprios Autores.

As regras do jogo, que seguem à seguir, foram entregues para os alunos antes do início do jogo.

Sejam bem-vindos ao Trigonometria para o ENEM!

Temos um círculo de 11 casas a serem percorridas no sentido horário. Cada aluno será identificado por um carrinho e as jogadas serão intermitentes, ou seja, ora é a sua vez, ora a do seu colega. A cada jogada você poderá cair em uma casa cinza, azul ou vermelha, sendo que estas correspondem a desafios de níveis básico, intermediário e avançado, respectivamente. Para o início do jogo, ambos os jogadores retiram uma carta da pilha de cartas escritas, no verso, SORTE, e depois revelam-na ao mesmo tempo. As cartas possuirão valor de um ângulo e, sendo assim, quem retirar o maior valor terá a vantagem de começar o jogo. Os jogadores deverão andar o número de casas descrito pelo valor do ângulo da carta SORTE que retirou. Por exemplo, se retirou 30 graus ele andará uma casa, lembrando que aquele que tirou o maior valor joga primeiro.

A dinâmica do jogo: ao cair em uma casa o jogador será surpreendido por um desafio, como dito anteriormente, a cor dela determinará o grau de dificuldade desse. Escolha uma dentre as cartas numeradas, que corresponde a um exercício do Caderno de Questões do nível de desafio indicado, que você deverá resolver. Após resolver a questão, o jogador deve virar a carta de desafio que constará a resposta e quantas casas ele deve andar.

Se você acertar, estará apto para a próxima jogada, terá apenas de explicar ao seu colega como chegou àquela resposta e esperá-lo jogar. Caso erre, terá mais uma chance para resolver corretamente. Se mesmo assim sua resposta estiver errada, o seu adversário terá a oportunidade de tentar resolver e ficar com a sua jogada. Vence o jogo quem chegar ao FIM primeiro. 


\section{Desenvolvimento da proposta}

Inicialmente, aplicamos um questionário 5 que tinha o objetivo de identificar o perfil dos alunos e o conhecimento que eles possuíam acerca do conteúdo de trigonometria, com o intuito de fazer uma comparação dos conhecimentos antes e depois da atividade. A última questão do questionário pedia para os alunos fazerem um mapa conceitual sobre trigonometria. Para isto, explicamos a eles o que é um mapa conceitual, o qual Moreira (2006, p.9) define, de forma mais ampla, como sendo "diagramas que indicam relações entre conceitos. Mais especificamente, podem ser interpretados como diagramas hierárquicos que procuram refletir a organização conceitual de um corpo de conhecimento ou de parte dele. $\mathrm{Ou}$ seja, sua existência deriva da estrutura conceitual de um conhecimento".

Ou seja, através do mapa, identificamos como o aluno estrutura o seu conhecimento sobre determinado assunto ou tópico. O objetivo de pedir para que os alunos fizessem este mapa conceitual era para analisarmos se o conteúdo foi revisado de maneira efetiva e, caso não tenha sido, poderemos pensar em alternativas para melhorar a proposta para outros momentos de aplicação dela.

Após a aplicação do questionário, demos início a uma breve revisão de tópicos de trigonometria. A revisão ocorreu de forma expositiva dialogada. Abordamos, nesta revisão, semelhança de triângulos, relações trigonométricas no triangulo retângulo, valores das funções seno, cosseno e tangente para os ângulos notáveis, ciclo trigonométrico, quadrantes e ângulos na circunferência.

Finalizada a revisão, demos início ao jogo. Pedimos às alunas que colocassem uma carteira de frente para a outra, pois uma aluna jogaria contra a outra. Como haviam 6 alunas, foram formadas 3 duplas. Em seguida, entregamos o material e fizemos a leitura das regras do jogo, esclarecendo as dúvidas e ressaltando que elas deveriam registrar todas as resoluções dos exercícios no Caderno de Questões.

A folha de registros que, no caso, era o Caderno de Questões, é indispensável em atividades com jogos. Além de ser uma ferramenta através da qual os pesquisadores podem verificar se os objetivos propostos foram atingidos, também possibilita analisar o desenvolvimento conceitual do aluno durante o jogo (BORIN, 2007).

Apesar de o jogo ser desenvolvido individualmente, sendo um aluno contra o outro, a interação e a troca de conhecimentos, previstas em atividades com jogos (BORIN, 2007), ocorreram através da regra "Se você acertar, estará apto para a próxima jogada, terá apenas de explicar ao seu colega como chegou àquela resposta (...)”. Neste sentido, Nacarato e Lopes

\footnotetext{
5 Este questionário possuía 7 questões, sendo 4 para identificar o perfil dos alunos, 1 para saber se já haviam participado de aulas de Matemática com jogos, 1 para verificar se os alunos possuíam dificuldades em trigonometria e 1 solicitando que os discentes fizessem um mapa conceitual sobre o conteúdo abordado no jogo.
} 
(2009) acreditam que explicar o seu raciocínio para o colega é um recurso muito interessante para o professor, que pode perceber o caminho do raciocínio e do pensamento do aluno e fazer intervenções mais pontuais, se necessário, além de estimular a argumentação nos alunos.

Durante o jogo, como foram formadas 3 duplas, foi fácil acompanhar a atividade, as discussões e dúvidas geradas, além de verificar se as regras estavam sendo cumpridas, pois cada dupla possuía um dos pesquisadores acompanhando, de perto, o jogo. Borin (2007, p.76) chama atenção para a importância do cumprimento das regras do jogo, apontando que "[...] os alunos se envolvem de tal forma com a preocupação em ganhar que, muitas vezes, tentam infringir as regras [...]”.

Após a realização do jogo, discutimos, com os alunos, as resoluções das questões apresentadas, para que eles pudessem refletir e analisar suas anotações, além de proporcionarmos um momento de discussão acerca do conteúdo de revisão abordado no jogo.

Por fim, aplicamos um outro questionário com o objetivo de compararmos os conhecimentos prévios e posteriores ao jogo dos alunos, através do mapa conceitual que pedimos para que eles fizessem novamente, além de proporcionar uma avaliação da atividade por parte dos alunos.

\section{Análise das resoluções apresentadas pelos alunos}

Os resultados encontrados foram obtidos através dos registros feitos pelos discentes no Caderno de Questões e das respostas apresentadas no questionário ${ }^{6}$ de avaliação da atividade.

A análise das resoluções apresentadas pelos alunos nas questões do nível básico foi feita de acordo com a Tabela 1.

Tabela 1. Erros/acertos referente às questões sorteadas de nível básico. Nível básico

\begin{tabular}{|c|c|c|c|c|}
\hline Questão & Conteúdo de trigonometria & $\begin{array}{l}\text { Alunos que sortearam/ } \\
\text { a questão }\end{array}$ & $\begin{array}{l}\text { Alunos que } \\
\text { a questão }\end{array}$ & $\begin{array}{l}\text { Alunos que } \\
\text { questão }\end{array}$ \\
\hline 1 & Razão trigonométrica sen. & 4 & 3 & 1 \\
\hline \multirow[t]{4}{*}{2} & $\begin{array}{l}\text { Razão trigonométrica seno ou } \\
\text { os no triângulo. }\end{array}$ & 4 & 3 & 1 \\
\hline & \begin{tabular}{|l|}
\multicolumn{2}{|c|}{ Razão } \\
trigonométrica no triângulo \\
retângulo seno ou cosseno.
\end{tabular} & 4 & 4 & 0 \\
\hline & \begin{tabular}{ll}
\multicolumn{2}{c}{ Semelhança } \\
triângulos.
\end{tabular} & 6 & 6 & 0 \\
\hline & $\begin{array}{c}\text { Ângulos } \\
\text { circunferência. }\end{array}$ & 5 & 3 & 2 \\
\hline
\end{tabular}

Fonte: Elaborada pelos autores.

O erro cometido na questão 1 se deve ao fato de o aluno ter confundido, no triângulo retângulo, o cateto oposto relativo ao ângulo de $70^{\circ}$ e a hipotenusa, pois este identificou

${ }^{6}$ Os critérios para a escolha das respostas apresentadas pelos discentes foram: a) Respostas com justificativas; b) Respostas que permitissem fazer conexão com o levantamento bibliográfico apresentado no relato de experiência; c) Coerência da resposta do discente à pergunta feita. 
corretamente a razão trigonométrica a ser utilizada para solução do problema, a razão seno, no entanto, não demonstrou domínio sobre “(...) a noção inicial e essencial para a aprendizagem das relações trigonométricas no triângulo retângulo, que é a identificação dos elementos nele definidos" (MOTA; JUCÁ; PINHEIRO, 2013, p.5).

Figura 2. Registro do aluno 4 na questão 1 do nível básico.

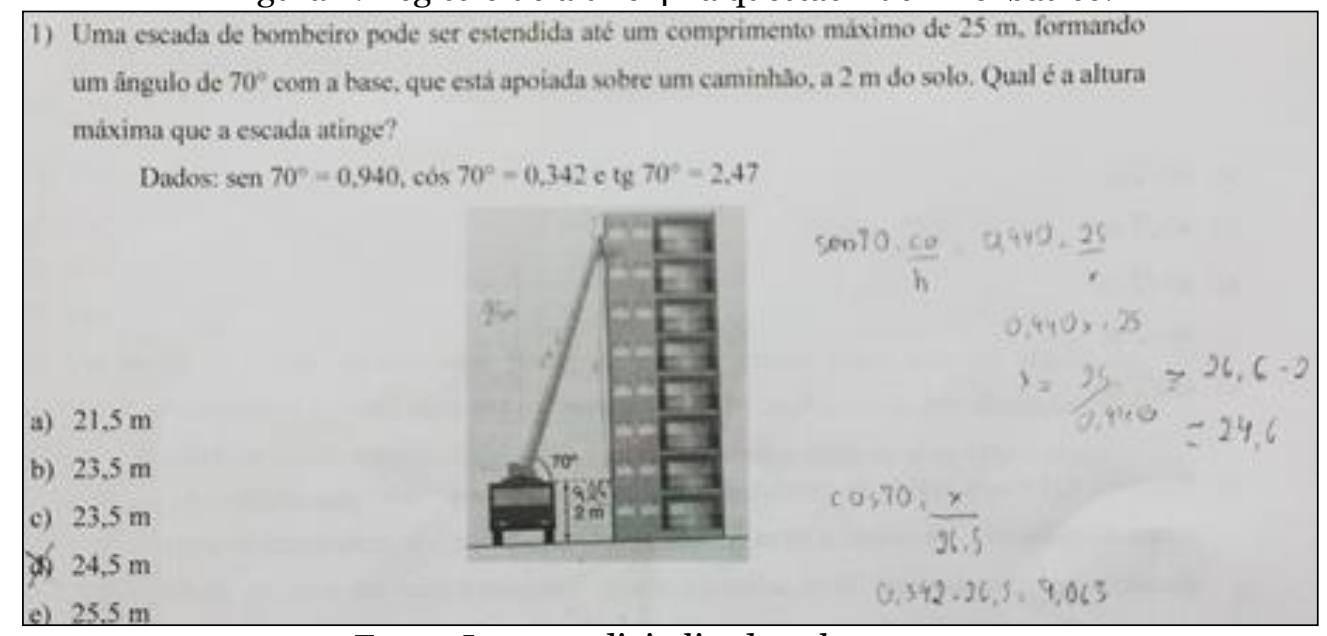

Fonte: Imagem digitalizada pelos autores

O erro na questão 2 se deve à não compreensão dos conceitos das razões trigonométricas seno e cosseno, pois o aluno considera, erroneamente, que o cosseno é a razão entre o cateto oposto e a hipotenusa. Este resultado vai ao encontro do que afirmam Silva e Neto (2006 apud MOTA; JUCÁ; PINHEIRO, 2013, p.8), quando estes apontam que "dificuldades referentes às relações trigonométricas no triângulo retângulo estão diretamente ligadas às dificuldades quanto às definições destas”.

Figura 3. Registro do aluno 3 na questão 2 do nível básico.

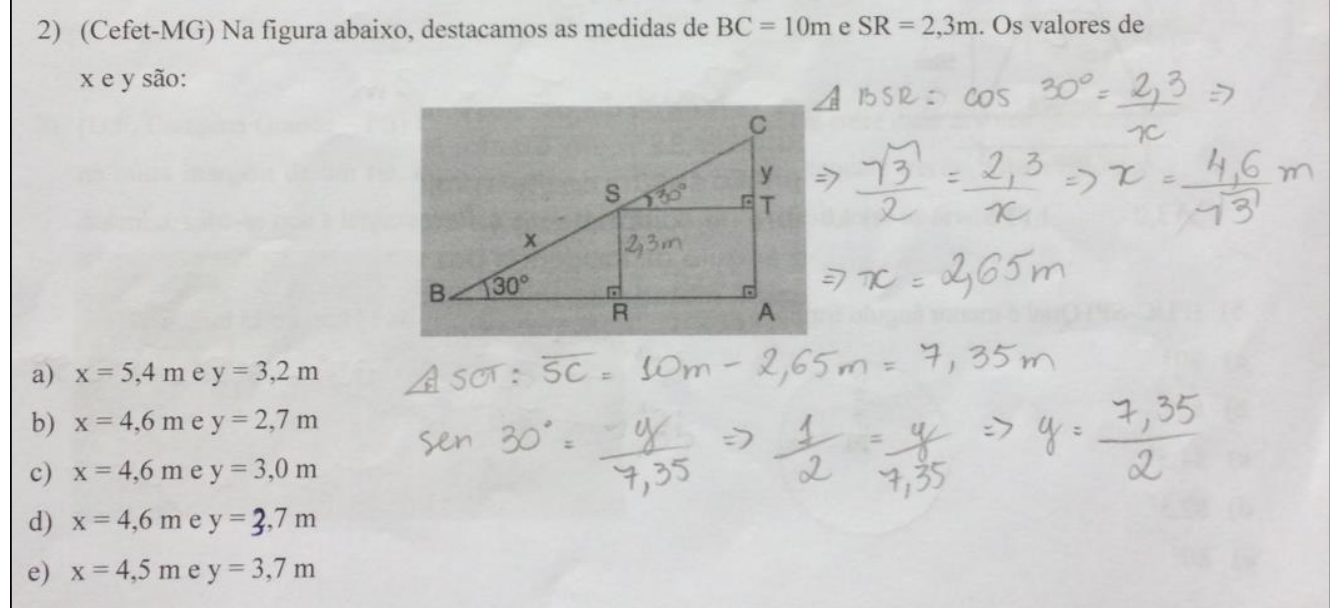

Fonte: Imagem digitalizada pelos autores.

ISSN 2526-2882 
Os dois alunos que erraram a questão 5 não apresentaram resoluções que nos possibilitassem análise do raciocínio, pois eles não apresentaram uma resposta final, mas cálculos desconexos. A análise das resoluções apresentadas pelos alunos nas questões do nível intermediário foi feita de acordo com a tabela à seguir.

Tabela 2 - Erros/acertos referente às questões sorteadas de nível intermediário. Nível intermediário

\begin{tabular}{|c|c|c|c|c|}
\hline Questão & Conteúdo de trigonometria & $\begin{array}{l}\text { Alunos que sortearam/ } \\
\text { resolveram a questão }\end{array}$ & Alunos que acertaram a & $\begin{array}{l}\text { Quantidade de alunos } \\
\text { n a questão }\end{array}$ \\
\hline 1 & $\begin{array}{l}\text { Ângulos no triângulo, triângulo } \\
\text { razão trigonométrica seno ou }\end{array}$ & 6 & 5 & 1 \\
\hline 2 & $\begin{array}{l}\text { Ângulos no triângulo, triângulo } \\
\text { razão trigonométrica seno ou }\end{array}$ & 3 & 1 & 2 \\
\hline 3 & $\begin{array}{l}\text { Razão trigonométrica seno, } \\
\text { tangente. }\end{array}$ & 2 & 2 & 2 \\
\hline 4 & Razão trigonométrica seno ou & 6 & 5 & 1 \\
\hline 5 & $\begin{array}{l}\text { Área de um } \quad \text { triângulo } \\
\text { o-se a medida de um lado e dos } \\
\text { triângulo. }\end{array}$ & 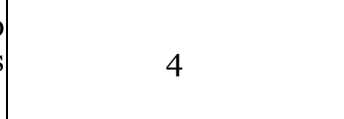 & 3 & 1 \\
\hline
\end{tabular}

Fonte: Elaborada pelos autores.

Na questão 1, o aluno considera, erroneamente, que o cosseno é a razão entre o cateto oposto e a hipotenusa, além de considerar, também equivocadamente, o cosseno de $30^{\circ}$ como sendo 0,5. Este erro remete novamente à não conceitualização das relações trigonométricas apontada por Silva e Neto (2006 apud MOTA; JUCÁ; PINHEIRO, 2013).

Na questão 2, dois alunos não visualizaram os triângulos isósceles, logo, não conseguiram finalizar a resolução. Nesse sentido, Fortes (2012 apud MOTA; JUCÁ; PINHEIRO, 2013, p.4) apontam que “[...] a dificuldade maior dos alunos [...] está centrada no conhecimento e identificação dos conceitos, como a identificação dos elementos do triângulo[...]”. Já o aluno que acertou a questão, apesar de ter identificado os triângulos isósceles, acabou não fazendo uso desta informação e, então, tornou sua resolução um pouco extensa.

Na questão 4, dos cinco alunos que a acertaram, quatro utilizaram o Teorema de Pitágoras para encontrar a resposta. $\mathrm{O}$ aluno que errou, até escreveu o Teorema de Pitágoras também, no entanto, não conseguiu finalizar o cálculo.

Por fim, na questão 5, os três alunos que acertaram a questão, utilizaram o conceito da tangente para encontrar o valor da altura do triângulo e, em seguida, utilizaram a fórmula da área do triângulo, obtendo sucesso na resolução. Entretanto, o aluno que errou, apenas obteve o valor da altura no triângulo, não concluindo a resolução.

A análise das resoluções apresentadas pelos alunos nas questões do nível avançado foi feita de acordo com a tabela abaixo. 
Tabela 3. Erros/acertos referente às questões sorteadas de nível avançado. Nível avançado

\begin{tabular}{c|c|c|c|c}
\hline Questão & Conteúdo de trigonometria & $\begin{array}{l}\text { Alunos que sortearam } \\
\text { resolveram a questão }\end{array}$ & $\begin{array}{l}\text { questão que acertou } \\
\text { qlunos } \\
\text { raram a questão }\end{array}$ \\
\hline 1 & Semelhança de triângulos. & 2 & 1 & 1 \\
\hline 2 & Semelhança de triângulos. & 1 & 0 & 1 \\
\hline 3 & $\begin{array}{l}\text { Semelhança de triângulos, } \\
\text { re suas áreas. }\end{array}$ & 0 & 0 & 0 \\
\hline 4 & Razão trigonométrica tangente & 0 & 0 & 0 \\
\hline 5 & $\begin{array}{l}\text { Área de triângulo, razão } \\
\text { étrica tangente, porcentagem. }\end{array}$ & 0 & 0 & 0 \\
\hline
\end{tabular}

Fonte: Elaborada pelos autores.

Na questão 1, os dois alunos que a fizeram souberam identificar corretamente a semelhança de triângulos, no entanto, somente um efetuou os cálculos corretamente e, o outro só montou a razão de semelhança, não a efetuando.

Já na questão 2, o aluno que a errou tentou encontrar algumas formas de semelhança no triângulo, não obtendo êxito para o término da resolução.

Percebe-se, pela Tabela 3, que nem todas as questões do nível avançado foram resolvidas. Isto se deve ao fato de o tempo programado para a atividade não ter sido suficiente. Assim, nenhuma das duplas conseguiram chegar à casa "FIM" do tabuleiro. Neste caso, acreditamos ser necessário, em uma próxima aplicação deste jogo, que seja reservado mais tempo para a toda a atividade, revisão, aplicação do jogo e discussão da atividade.

\section{Análise da intervenção realizada}

Com relação ao envolvimento dos alunos na atividade, em um primeiro momento, eles ficaram receosos com as regras. Como tinham poucos alunos, foi possível acompanhar as duplas de perto e, então, achamos melhor que, na vez de cada jogador, ambos resolvessem a mesma questão para que o jogo não demorasse tanto e o adversário não ficasse parado enquanto o jogador da rodada resolvesse as questões.

Como mediadores, tentamos não influenciar no resultado do jogo, mas sim incentivar aos alunos e tirar suas dúvidas quando ambos não conseguiam resolver, ou intervindo caso um jogador não conseguisse explicar a questão ao outro, de forma a fazer com que o jogo fluísse. Esse comportamento vai ao encontro, mais uma vez, do que destaca Grando (1995) quanto ao papel mediador do professor.

Além dos registos feitos pelos alunos durante a realização da atividade, consideramos que as respostas apresentadas por eles nos questionários inicial e final também nos permitem analisar se o objetivo principal da atividade, ou seja, trabalhar trigonometria e fixar o conteúdo através de um jogo, foi alcançado. 
No questionário inicial, além de coletar o perfil dos alunos, perguntamos se tinham dificuldade em aprender conteúdos de trigonometria. Dois alunos não se lembravam do que se tratava a trigonometria, outros dois disseram que que não tinham dificuldade, pois tinham facilidade e/ou interesse na área de exatas, e assim o conteúdo ficava interessante. Um aluno disse que tinha dificuldade, mas que, ao fixar o conteúdo, aprendia; que era justamente a proposta do nosso jogo, e por fim, uma aluna disse que tinha dificuldade em qualquer coisa que envolvesse a matemática. Como dito anteriormente, alguns alunos possuem bloqueio com a matemática e então esperávamos que, com o jogo, o conteúdo se tornasse mais interessante.

No questionário de avaliação da atividade, perguntamos se o uso de jogos nas aulas de matemática pode facilitar a aprendizagem, todos os alunos afirmaram que sim, relatando que o jogo os deixam mais envolvidos e as aulas ficam mais divertidas, o que faz com que consigam tirar dúvidas e entender partes do conteúdo que não haviam entendido na aula tradicional, a qual, eles denominaram "monótona".

As respostas apresentadas pelos alunos corroboram o pensamento de Rizzo (1996, apud JELINEK, 2005, p. 55), que destaca: "são as atividades lúdicas que aliam desafio ao prazer, que devem predominar entre as atividades oferecidas às crianças, pois essas, seguidas de atividades criadoras, estimulam a organização e construção do pensamento e a expressão de ideias."

A segunda pergunta tratava da dificuldade em estudar os conceitos envolvidos na trigonometria e se o jogo auxiliou a reforçar os conteúdos de trigonometria. Todos os alunos afirmaram que o jogo ajudou a reforçar o conteúdo abordado na atividade.

Na terceira pergunta, pedimos aos alunos que sugerissem atividades diferenciadas para facilitar a aprendizagem dos conteúdos matemáticos. Não foi apresentada nenhuma sugestão, porém a resposta de um aluno mostra, nitidamente, que o objetivo do jogo foi alcançando, uma vez que, segundo Borin (2007), os jogos de treinamento, que se caracterizam pela repetição, devem ter claros os objetivos que quer alcançar para não se tornar mecânico, e foi isso que o jogo propôs: reforçar de forma prazerosa o conteúdo de trigonometria.

Figura 4. Resposta do Aluno 5 à pergunta 3 do questionário final.

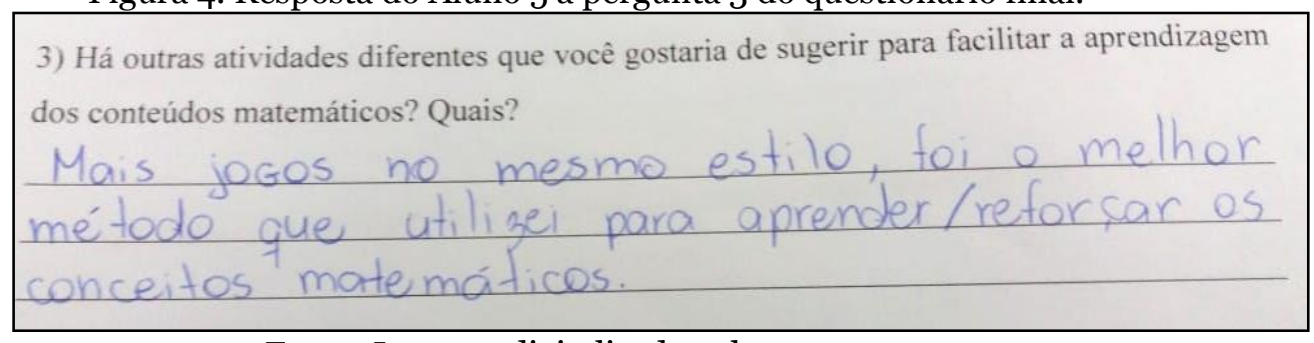

Fonte: Imagem digitalizada pelos autores.

Para finalizarmos, pedimos que os alunos elaborassem, novamente, um mapa conceitual acerca do tema trigonometria, para analisarmos se a aplicação do jogo propiciou um ISSN 2526-2882 
avanço nos conhecimentos dos alunos sobre o conteúdo abordado. Para melhor compreensão, analisaremos os dois mapas juntos. $\mathrm{O}$ aluno 6 não organizou nenhum mapa conceitual. Os Alunos 2 e 4 não apresentaram avanços no segundo mapa em relação ao primeiro. Já o Aluno 1, em seu primeiro mapa conceitual, não escreveu nada. Porém, no segundo, já conseguiu fazer algumas relações e elencar alguns conceitos da trigonometria. O Aluno 3, em seu primeiro mapa, apresentou as três relações trigonométricas no triângulo retângulo. E no segundo mapa conceitual, mostrou novos conceitos, o que nos leva a crer que estes conceitos foram relembrados com a aplicação do jogo.

Figura 5. Mapa Conceitual Final do Aluno 3.

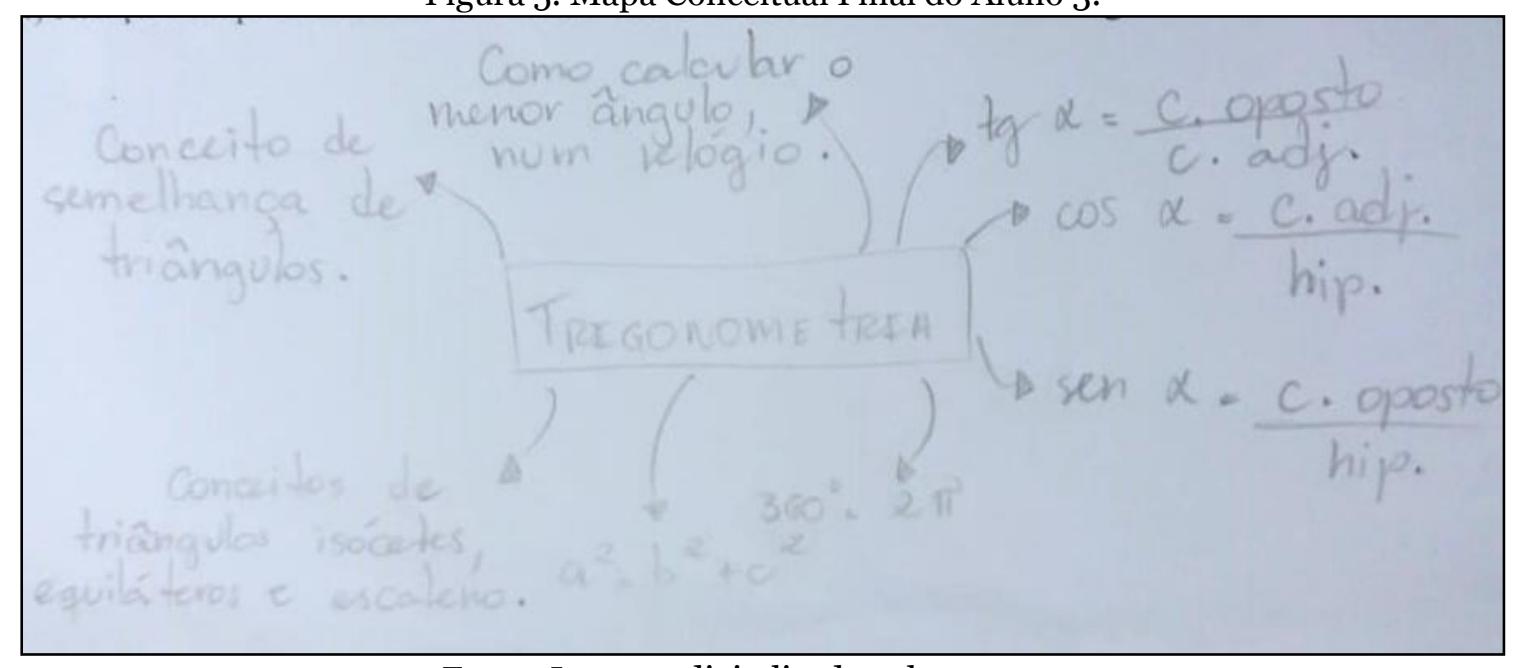

Fonte: Imagem digitalizada pelos autores.

Já o Aluno 5, também apresentou apenas conceitos de relações trigonométricas no mapa inicial, enquanto, no final, demonstrou certo conhecimento, mesmo que não tenha feito um mapa conceitual, pois não apresentou ligações entre os conceitos.

Figura 6. Mapa Conceitual Inicial do Aluno 5.

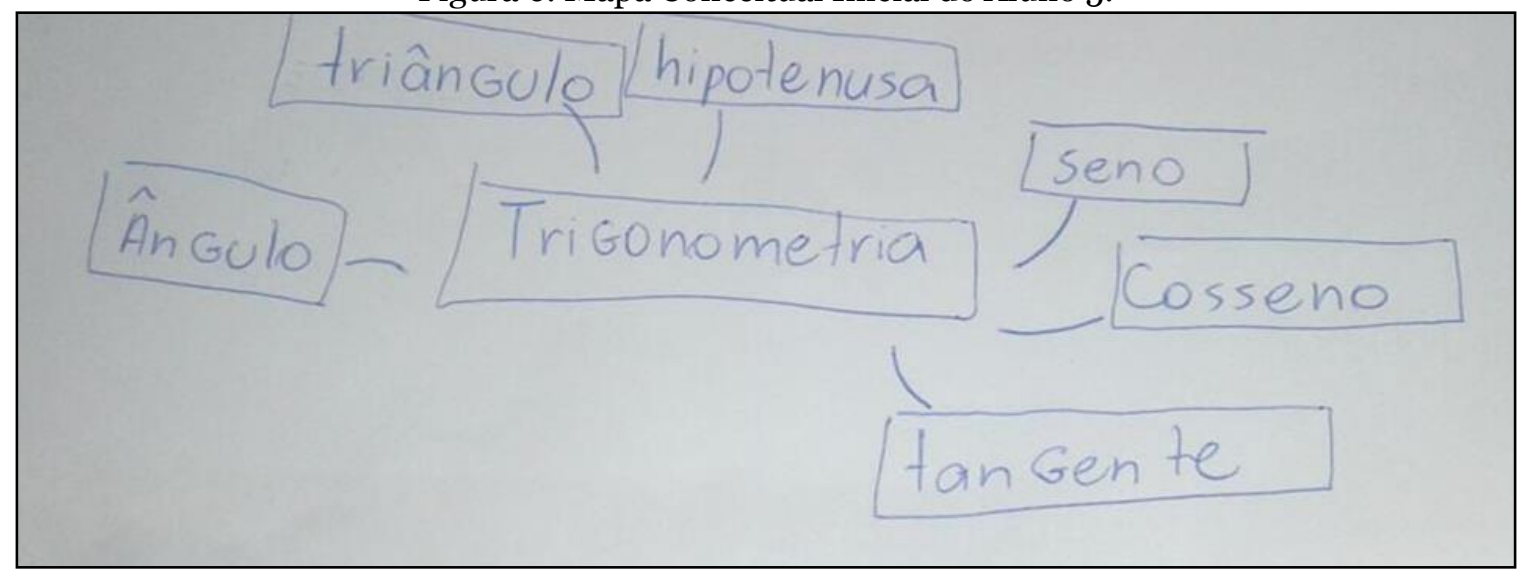

Fonte: Imagem digitalizada pelos autores. 
Podemos perceber que os alunos não elaboraram mapas conceituais, pois não realizaram relações hierárquicas entre os conceitos, outro aspecto que poderá ser melhorado nas próximas aplicações, pois apesar dos alunos falarem que sabiam o que era mapa conceitual, eles mostraram não terem domínio sobre o assunto, portanto, em outra aplicação, podemos explicar e apresentar exemplos de mapas conceituais.

Segundo Moreira (2006, p. 18), podemos utilizar os mapas conceituais para avaliação de aprendizagem "avaliação não com o objetivo de testar conhecimento e dar uma nota ao aluno, a fim de classificá-lo de alguma maneira, mas no sentido de obter informações sobre o tipo de estrutura que o aluno vê para um dado conjunto de conceitos”. E apesar de, tecnicamente os alunos não terem feito mapas conceituais, foi possível avaliar que os esquemas dos alunos que se envolveram com a atividade apresentaram novos conceitos em relação ao primeiro que haviam escrito e, então, identificamos isto como um avanço para a aprendizagem dos alunos.

\section{Considerações finais}

Acreditamos que a aplicação do jogo Trigonometria para o ENEM produziu resultados satisfatórios. O objetivo principal proposto pela atividade - rever e reforçar conteúdos de trigonometria, em especial, razões trigonométricas e semelhança de triângulos - foi alcançado.

As folhas de registro foram importantes para analisarmos os erros cometidos pelos alunos e, então, os discutirmos após a aplicação do jogo, gerando, desta forma, um momento enriquecedor de discussão e aperfeiçoamento das resoluções apresentadas e conceitos abordados nos exercícios do Caderno de Questões.

Outros benefícios mais gerais foram identificados com a aplicação do jogo, como a motivação dos alunos para a aprendizagem e a socialização e colaboração entre eles. Também percebemos que os alunos assumem, durante o jogo, um papel ativo no seu processo de aprendizagem, enquanto o professor (experiência vivenciada pelos licenciandos envolvidos na pesquisa) passa a ser o medidor deste processo.

Enquanto futuros docentes, acreditamos que os benefícios obtidos com a aplicação do jogo Trigonometria para o ENEM, nos motivam e instigam a planejarmos e propormos novas atividades com jogos em sala de aula, sejam elas em futuras oportunidades como docentes ou em atividades do estágio.

\section{Referências}

ALVES, E. M. S. A ludicidade e o ensino de matemática. 4 ed. Campinas: 2007.

BARBOSA, C. P.et al. A utilização de jogos como metodologia de ensino da matemática: uma experiência com alunos do $6^{\circ}$ ano do ensino fundamental. Forscience, [s.l.], v. 3, n. 1, p.70-86, 30 jun. 2015. ForScience: Revista Cientifica do IFMG. Disponível em: 
<http://www.forscience.ifmg.edu.br/forscience/index.php/forscience/article/view/ 107>. Acesso em: 09 maio 2018.

BORIN, J. Jogos e resolução de problemas: uma estratégia para as aulas de matemática. 6 ed. São Paulo: 2007.

D’AMBrosio, B. S. Como ensinar matemática hoje? Temas e Debates. SBEM. Brasília. Ano II. $\quad$ n. ${ }^{\circ}$. $1989 . \quad$ p. $15-19$. Disponível em: https://edisciplinas.usp.br/pluginfile.php/1953133/mod_resource/content/1/\%5B1 989\%5D\%20DAMBROSIO\%2C\%20B\%20-

\%20Como\%20Ensinar\%20Matemática\%20Hoje.pdf. Acesso em: 01 ago. 2018.

DIONIZIO, F. Q.; BRANDT, C. F. Análise das dificuldades apresentadas pelos alunos do ensino médio em trigonometria. In: Congresso Nacional de Educação-EDUCERE, 10., 2011, Curitiba. Anais... 2011. PUCPR. Disponível em: http://educere.bruc.com.br/CD2011/pdf/4728_2885.pdf. Acesso em: 18 jul. 2018.

GRANDO, R. C. O conhecimento matemático e o uso de jogos na sala de aula. 2000. Tese (Doutourado) - Faculdade de educação, Universidade Estadual de Campinas, Campinas.

- O jogo suas possibilidades Metodológicas no processo ensinoaprendizagem da Matemática. 1995. Dissertação (Mestrado em educação) Faculdade de educação, Universidade Estadual de Campinas, Campinas.

IEZZI, G. et al. Matemática. Volume Único. $5^{0}$ ed. São Paulo: Atual. 2011.

INEP. Instituto Nacional de Estudos e Pesquisas Educacionais Anísio Teixeira. Provas e Gabaritos. Out. 2015. Disponível em: < http://portal.inep.gov.br/provas-egabaritos>. Acesso em: 28 jan. 2018.

JELINEK, K. R. Jogos nas aulas de matemática: brincadeira ou aprendizagem? 0 que pensam os professores? 2005. Dissertação (Mestrado em Educação em Ciências e Matemática), Universidade Católica do Rio Grande do Sul, Porto Alegre. Disponível em: http://tede2.pucrs.br/tede2/bitstream/tede/3487/1/332635.pdf. Acesso em: 20 jul. 2018.

MOREIRA, M. A. (2006b). Mapas conceituais \& diagramas V. Porto Alegre: Edição do autor. 103p.

MOTA, T. B.; JUCÁ, R. S.; PINHEIRO, C. A. M. Uma análise de erros nas relações trigonométricas no triângulo retângulo. In: XI Encontro Nacional de Educação Matemática, 11., 2013, Curitiba. Anais... Curitiba: SBEM, 2013. p. 1-15. Disponível em:

http://www.educadores.diaadia.pr.gov.br/arquivos/File/dezembro2013/matematic a_artigos/artigo_mota_juca_pinheiro.pdf > . Acesso em: 10 ago. 2018. 
NACARATO, A. M.; LOPES, C. E. Escritas e leituras na educação matemática. Belo Horizonte: Autêntica, 2009.

PEREIRA, E.; GUERRA, E. A. A utilização de applets no geogebra para a aprendizagem da trigonometria no ensino médio. Revista de Ensino de Ciências e Matemática, v. 7, n. 3, p. $2016.72, \quad$ Disponível em: http://revistapos.cruzeirodosul.edu.br/index.php/rencima/article/view/1073. Acesso em: 10 ago. 2018.

SELVA, R. K; CAMARGO, M. O jogo matemático como recurso para a construção do conhecimento. In: Encontro Gaúcho de educação matemática, 10, 2009, Ijuí. Anais... Ijuí: . Disponível em: http://www.projetos.unijui.edu.br/matematica/cd_egem/fscommand/CC/CC_4.pd f. Acesso em: 11 set. 2018.

SILVA, D. L. Jogos Matemáticos nas Aulas do Ensino Médio: Um Estudo dos Trabalhos Publicados no ENEM. 2013. Trabalho de Conclusão de Curso (Licenciatura em Matemática) - Instituto Federal de Educação, Ciência e Tecnologia de São Paulo, São Paulo, 2013. Disponível em: https://eadcampus.spo.ifsp.edu.br/pluginfile.php/7465/mod_resource/content/o/ TCC_David.pdf. Acesso em: 01 jul. 2018.

TEIXEIRA, L. R. M. Dificuldades e erros na aprendizagem da matemática. In: ENCONTRO PAULISTA DE EDUCAÇÃO MATEMÁTICA, 7., 2004, São Paulo. Anais.... São Paulo, 2004. $\quad$ p. $\quad 1 \quad-14 . \quad$ Disponível em: http://miltonborba.org/CD/Interdisciplinaridade/Anais_VII_EPEM/mesas_redon das/mr14-Leny.doc. Acesso em: 09 maio 2018.

\section{Biografia Resumida}

Lúcia Helena Costa Braz: Docente do curso de Licenciatura em Matemática do Instituto Federal de Educação, Ciência e Tecnologia de Minas Gerais campus Formiga. Mestre em Matemática pela Universidade Federal de Lavras;

Lattes: http://lattes.cnpq.br/8127215627397170

Contato: lucia.helena@ifmg.edu.br

Brenda Cristina Almeida: licenciada em Matemática pelo Instituto Federal de Educação, Ciência e Tecnologia de Minas Gerais campus Formiga;

Lattes: http://lattes.cnpq.br/o466941736421467

ISSN 2526-2882 
Contato: brendaalmeidasantos@hotmail.com

Leonardo Tavares Campos: licenciando em Matemática pelo Instituto Federal de Educação, Ciência e Tecnologia de Minas Gerais campus Formiga;

Lattes: http://lattes.cnpq.br/9474908815971383

Contato: leotcampos2@gmail.com

Vinícius Silveira Ibrahim: licenciando em Matemática pelo Instituto Federal de Educação, Ciência e Tecnologia de Minas Gerais campus Formiga;

Lattes: http://lattes.cnpq.br/7888669446396499

Contato: ibrahimvinicius13@gmail.com 